\title{
The CAIDE Dementia Risk Score and the Honolulu-Asia Aging Study
}

\author{
E. Julia Chosy ${ }^{a}$ Steven D. Edland ${ }^{b}$ Noele Gross $^{a}$ Marnie J. Meyer ${ }^{a}$ \\ Catherine Y. Liu ${ }^{a}$ Lenore J. Launer ${ }^{c}$ Lon R. White ${ }^{a}$ \\ apacific Health Research and Education Institute, Honolulu, HI, USA; b University of \\ California at San Diego, San Diego, CA, USA; ${ }^{\circ}$ National Institute on Aging, National \\ Institutes of Health, Bethesda, MD, USA
}

\section{Keywords}

Alzheimer's dementia - Assessment measures · CAIDE - Cardiovascular risk factors . Honolulu-Asia Aging Study · Risk factors

\begin{abstract}
Introduction: The CAIDE (Cardiovascular Risk Factors, Aging, and Incidence of Dementia) dementia risk score is based on demographic, genetic, and modifiable risk factors in midlife and has been shown to be predictive of later-life dementia. Objective: To test the predictive capacity of the CAIDE dementia risk score among a cohort of Japanese-American men. Methods: Midlife measures were obtained from a sample of 3,582 Japanese-American men in the Honolulu Heart Program (1965-1968, average age $=53.1$ years). A follow-up exam in 1991 (average age $=77.8$ years) assessed cognitive impairment using the Cognitive Abilities Screening Instrument (CASI). Severe cognitive impairment was defined as a CASI score <60. Results: In this cohort, the CAIDE dementia risk score demonstrates significant association with laterlife severe cognitive impairment $(\mathrm{OR}=1.477,95 \% \mathrm{Cl}: 1.39-1.58)$. However, the area under the receiver-operating characteristic curve $c$-statistics suggests poor predictive ability $(c=0.645$, $95 \% \mathrm{Cl}: 0.62-0.67)$. Using a score cut-point of 10 , the accuracy is acceptable $(0.82)$, but the sensitivity is low (0.50). Conclusion: While the CAIDE dementia risk score at midlife is associated with later development of cognitive impairment in Japanese-American men, its predictive capacity in this population is weak.

(C) 2020 S. Karger AG, Basel
\end{abstract}

\section{Introduction}

Recent reviews have identified over 70 different prediction models for the detection of individuals at high risk for dementia or Alzheimer's disease [1-3]. They vary widely based on the type of predictors they include, the age at screening, the length of follow-up time, and the 
sample from which the model was derived (e.g., population, primary care, cohort). Although some of these risk models perform well, none has shown high predictive capacity across a range of populations. Stephan et al. [2] suggest rather than add to an already saturated pool, researchers should focus on validating and improving existing risk models. In this study, we applied a widely known risk score for dementia, the CAIDE (Cardiovascular Risk Factors, Aging, and Incidence of Dementia) dementia risk score, to a population demographically distinct from the cohort in which the score was developed.

The CAIDE dementia risk score was developed using a large population-based cohort from Finland [4]. Participants were first examined in midlife, when extensive health data were collected, then followed over 20 years for the development of dementia. Based on data from the study, a risk score for predicting future dementia was constructed from multiple demographic and midlife measures. Later, the score was modified to place greater weight on age and education and to include carrier status for the apolipoprotein $\varepsilon 4$ allele (APOE $\varepsilon 4)$. Though it demonstrated moderate predictive capacity in the Finnish cohort (c-statistics = $0.78,95 \%$ CI: $0.72-0.84$ ), validation among additional cohorts is important to understand the generalizability of the risk score.

The Honolulu Heart Program (HHP) began in 1965 with a cohort of over 8,000 JapaneseAmerican men born between 1900 and 1919 and living on the island of Oahu, Hawaii. They were followed over time and the cohort evolved into the Honolulu-Asia Aging Study (HAAS), which was designed to examine cognitive function and diseases of aging [5]. As such, data exist on both the midlife health of the participants and on later life cognitive function. We used these data to examine the predictive ability of the CAIDE dementia risk score in this population.

\section{Methods}

\section{Study Population}

Study participants came from the HAAS, which evolved from the HHP, both of which were reviewed and approved by the Institutional Review Board of Kuakini Medical Center, Honolulu, Hawaii. Beginning in 1965, a large cohort of Japanese men born between 1900 and 1919 and living on the island of Oahu, Hawaii, $(n=$ $8,006)$ were followed and reexamined two additional times separated by approximately 3-year intervals. A fourth exam was conducted from 1991 to 1993 for the remaining HHP members who agreed to participate. This was the baseline for the HAAS, which was designed to study cognitive function and diseases of aging [5]. The group of 3,734 men represented almost $80 \%$ of the surviving HHP cohort. Excluding respondents with missing data, the final sample for this study was 3,582 participants. The average length of time between the first and fourth exams was 25.2 years ( \pm 1.1 years).

\section{Definition of Cognitive Impairment}

The Cognitive Abilities Screening Instrument (CASI) is a comprehensive screening instrument specifically designed for the cross-cultural assessment of cognitive impairment and dementia [6]. It combines measures of attention, concentration, orientation, memory, language, visual construction, abstraction, and judgement to create a composite score ranging from 1 to 100 . For this analysis, a CASI score of $<60$ was used to indicate severe cognitive impairment (SCI) [7]. The recorded CASI score at the fourth exam was used to determine the presence $(n=189)$ or absence $(n=3,393)$ of SCI.

\section{CAIDE Dementia Risk Score}

The CAIDE dementia risk score is comprised of dichotomized values for sex, systolic blood pressure (SBP), body mass index (BMI), total cholesterol, physical activity, and APOE \&4 status, as well as tertiles describing age and education in the original cohort. With the exception of $A P O E \varepsilon 4$ status, measures for each factor were taken during the first HHP exam (1965-1968) when the average age of the cohort was 53.1 years. Age, education, and physical activity were self-reported, while SBP, BMI, and blood cholesterol measures were obtained by health care professionals. The physical activity index was created using the average time 
Table 1. Comparison of characteristics among respondents who had or had not developed severe cognitive impairment (CASI score $<60$ ) by exam 4

\begin{tabular}{|c|c|c|c|c|}
\hline \multirow[t]{2}{*}{ Characteristic } & \multicolumn{2}{|l|}{ SCI } & \multirow[t]{2}{*}{$p$ value } & \multirow[t]{2}{*}{ OR $(95 \% \mathrm{CI})$} \\
\hline & present $(n=189)$ & absent $(n=3,393)$ & & \\
\hline Age at exam 1 , years & $58.4 \pm 5.4$ & $52.3 \pm 4.4$ & $<0.0001$ & $1.256(1.22-1.29)$ \\
\hline Education, years & $8.0 \pm 2.9$ & $10.6 \pm 3.2$ & $<0.0001$ & $0.731(0.69-0.77)$ \\
\hline Systolic blood pressure, mm Hg & $134.0 \pm 21.4$ & $129.8 \pm 18.3$ & 0.0094 & $1.011(1.00-1.02)$ \\
\hline Body mass index, $\mathrm{kg} / \mathrm{m}^{2}$ & $23.8 \pm 3.0$ & $23.9 \pm 2.8$ & 0.7226 & $0.991(0.94-1.04)$ \\
\hline Cholesterol, mmol/L & $5.6 \pm 0.9$ & $5.7 \pm 0.9$ & 0.5239 & $0.949(0.81-1.12)$ \\
\hline Physically active & $174(92.1)$ & $2,803(82.6)$ & 0.0007 & $2.441(1.43-4.17)$ \\
\hline$A P O E \& 4$ carrier & 37 (19.6) & $625(18.4)$ & 0.6902 & $1.078(0.75-1.56)$ \\
\hline CAIDE dementia risk score & $9.49 \pm 2.0$ & $7.21 \pm 2.4$ & $<0.0001$ & $1.477(1.39-1.58)$ \\
\hline
\end{tabular}

Values are given as mean \pm SD or $n(\%)$.

$A P O E \varepsilon 4$, apolipoprotein allele $\varepsilon 4$; CASI, Cognitive Abilities Screening Instrument; CI, confidence interval; OR, odds ratio; SCI, severe cognitive impairment; SD, standard deviation.

Bold identifies significant results.

$p$ value is based on Satterthwaite's $t$ value or Pearson's $\chi^{2}$. OR and 95\% CI for parameter estimate.

spent at different levels of physical activity (none to heavy) weighted by the level of oxygen consumption associated with each activity (see Donahue et al. [8] for more details). Genetic testing to acquire APOE $\varepsilon 4$ carrier status was conducted at the fourth exam (1991-1993). The possible range for the CAIDE dementia risk score is $0-18$. In this all-male cohort, the observed range was 1-15.

\section{Statistical Analyses}

Satterthwaite's $t$ tests and Pearson's $\chi^{2}$ tests were used to compare respondents who had developed SCI to those who had not. Basic logistic regression was used to assess the effect of each component of the CAIDE dementia risk score on the prediction of subsequent development of SCI. c-statistics were derived from the area under the receiver-operating characteristic curve. Risk score quartiles were identified using the distribution of the CAIDE dementia risk score in the sample and were utilized to compare SCI prevalence and relative risk. We report predictive capacity (i.e., sensitivity, specificity, positive and negative predictive values, and accuracy) for two different cut-off points of the score: high risk $=9-18$ and high risk $=10-18$.

\section{Results}

Table 1 compares respondents who had developed SCI (CASI score <60) by exam 4 with those who had not. Those who had developed SCI were significantly older ( 58.4 vs 52.3 years, $p<0.0001$ ), had less education (8.0 vs. 10.6 years, $p<0.0001$ ), had higher SBP (134 vs. 130 $\mathrm{mm} \mathrm{Hg}, p=0.0094)$, and were physically more active ( $p=0.0007)$. The CAIDE dementia risk score was also significantly higher ( 9.49 vs. $7.21, p<0.0001$ ) among those who developed SCI. There was a $48 \%$ increase in the odds of SCI for each 1-point increase in the risk score (OR = 1.477, 95\% CI: 1.39-1.58). BMI, total cholesterol, and APOE $\varepsilon 4$ carrier status demonstrated no difference between the two groups.

The values used to compute the CAIDE dementia risk score are shown in Table 2. For each component of the score, beta coefficients and odds ratios for the development of SCI from logistic regression models are given. In the HAAS cohort, age, education, BMI, physical activity, and $A P O E \& 4$ status were associated with the development of SCI in univariate analyses. Table 2 also displays the c-statistics, or area under the receiver-operating characteristic curve, for each component of the score as a measure of its predictive ability. The c-statistics gives an 
Dementia

Cognitive Disorders

\begin{tabular}{l|l}
\hline Dement Geriatr Cogn Disord 2019;48:164-171 \\
\hline DOI: 10.1159/000504801 & $\begin{array}{l}\text { @ 2020 S. Karger AG, Basel } \\
\text { www.karger.com/dem }\end{array}$ \\
\hline
\end{tabular}

Table 2. Components of the CAIDE dementia risk score

\begin{tabular}{|c|c|c|c|c|c|}
\hline CAIDE component & $\begin{array}{l}\text { CAIDE } \\
\text { dementia risk } \\
\text { score }\end{array}$ & $\beta$ coefficient & $p$ value & OR $(95 \% \mathrm{CI})$ & c-statistics $(95 \% \mathrm{CI})$ \\
\hline \multicolumn{6}{|l|}{ Age at exam 1} \\
\hline$<47$ years & 0 & 0 (ref) & & & \\
\hline 47-53 years & 3 & -0.2012 & 0.0858 & $1.126(0.59-2.16)$ & \\
\hline$>53$ years & 5 & 0.5214 & $<0.0001$ & $2.320(1.21-4.45)$ & $0.587(0.57-0.61)$ \\
\hline \multicolumn{6}{|l|}{ Education } \\
\hline$\geq 10$ years & 0 & 0 (ref) & & & \\
\hline 7-9 years & 3 & -0.0568 & 0.3589 & $1.829(1.53-2.19)$ & \\
\hline $0-6$ years & 4 & 0.7173 & $<0.0001$ & $3.966(3.06-5.15)$ & $0.611(0.59-0.63)$ \\
\hline \multicolumn{6}{|l|}{$\operatorname{Sex}^{\mathrm{a}}$} \\
\hline Women & 0 & NA & NA & NA & \\
\hline Men & 1 & NA & NA & NA & NA \\
\hline \multicolumn{6}{|c|}{ Systolic blood pressure } \\
\hline$\leq 140 \mathrm{~mm} \mathrm{Hg}$ & 0 & 0 (ref) & & & \\
\hline$>140$ mm Hg & 2 & 0.0667 & 0.1530 & $1.143(0.95-1.37)$ & $0.513(0.49-0.53)$ \\
\hline \multicolumn{6}{|l|}{ Body mass index } \\
\hline$\leq 30 \mathrm{~kg} / \mathrm{m}^{2}$ & 0 & 0 (ref) & & & \\
\hline$>30 \mathrm{~kg} / \mathrm{m}^{2}$ & 2 & 0.276 & 0.0418 & $1.737(1.02-3.96)$ & $0.506(0.50-0.51)$ \\
\hline \multicolumn{6}{|l|}{ Total cholesterol } \\
\hline$\leq 6.5 \mathrm{mmol} / \mathrm{L}$ & 0 & 0 (ref) & & & \\
\hline$>6.5 \mathrm{mmol} / \mathrm{L}$ & 1 & -0.042 & 0.4576 & $0.919(0.74-1.15)$ & $0.506(0.49-0.52)$ \\
\hline \multicolumn{6}{|l|}{ Physical activity } \\
\hline Active & 0 & 0 (ref) & & & \\
\hline Inactive & 1 & -0.2111 & 0.0006 & $0.656(0.52-0.83)$ & $0.527(0.51-0.54)$ \\
\hline \multicolumn{6}{|l|}{$A P O E \varepsilon 4$ status } \\
\hline Non-carrier & 0 & 0 (ref) & & & \\
\hline Carrier & 2 & 0.2149 & $<0.0001$ & $1.537(1.26-1.87)$ & $0.535(0.52-0.55)$ \\
\hline Total & 18 & & & & $0.645(0.62-0.67)$ \\
\hline
\end{tabular}

There are eight parts of the CAIDE dementia risk score, each with a designated value. An individual's CAIDE dementia risk score is the sum of the values for each of these eight items. Beta coefficients and odds ratios for the development of SCI (CASI score $<60$ ) in the cohort are shown for each component, as is the area under the receiver-operating characteristic curve (c-statistics).

$A P O E$ \&4, apolipoprotein allele \&4; CAIDE, Cardiovascular Risk Factors, Aging and Incidence of Dementia; CASI, Cognitive Abilities Screening Instrument; CI, confidence interval; NA, not applicable; OR, odds ratio; ref, reference category; SCI, severe cognitive impairment.

Bold identifies significant results.

$p$ value is based on Wald's $\chi^{2}$. OR and 95\% CI for parameter estimate. c-statistic values, or area under the receiver-operating curve (AUC), and 95\% CI for each component and for the combined score.

${ }^{\text {a }}$ Estimates not available for an all-male cohort.

estimate of the discriminative ability of the test, with a value of 1.0 representing perfect prediction and 0.5 being the same as chance. The individual components of the CAIDE dementia risk score demonstrate discriminative ability ranging from 0.506 (BMI, cholesterol) to 0.611 (education). Taking all components of the score together, the c-statistics is 0.645 (95\% CI: 0.62-0.67).

Table 3 shows the prevalence of SCI across the quartiles of the CAIDE dementia risk score. In the lowest quartile, the prevalence of SCI is $0.7 \%$ compared to $14.4 \%$ in the highest quartile. The relative risk of developing SCI based on risk score is shown using the lowest quartile as the reference category. Those respondents with CAIDE dementia risk scores in the highest 
Dementia

and Geriatric
Cognitive Disorders

Table 3. Prevalence of SCI at exam 4 across the quartiles of the CAIDE dementia risk score and relative risk of SCI development
Table 4. Predictive capacity of the CAIDE dementia risk score in the HAAS cohort

\begin{tabular}{l|l}
\hline Dement Geriatr Cogn Disord 2019;48:164-171 \\
\hline DOI: 10.1159/000504801 & $\begin{array}{l}\text { c 2020 S. Karger AG, Basel } \\
\text { www.karger.com/dem }\end{array}$ \\
\hline
\end{tabular}

\begin{tabular}{llll}
\hline $\begin{array}{l}\text { CAIDE } \\
\text { dementia risk } \\
\text { score }\end{array}$ & $\begin{array}{l}\text { SCI/All, } \\
\text { of SCI }\end{array}$ & $\begin{array}{l}\text { Prevalence } \\
\text { RR (95\% CI) }\end{array}$ \\
\hline $1-5$ & $6 / 860$ & $0.7 \%$ & 1.000 \\
$6-7$ & $22 / 1,147$ & $1.9 \%$ & $2.014(0.99-4.10)$ \\
$8-9$ & $66 / 916$ & $7.2 \%$ & $\mathbf{6 . 0 1 8}(\mathbf{2 . 7 9 - 1 2 . 9 6 )}$ \\
$10-18$ & $95 / 660$ & $14.4 \%$ & $\mathbf{1 0 . 1 3 1 ( 4 . 6 6 - 2 2 . 0 4 )}$ \\
\hline
\end{tabular}

CAIDE, Cardiovascular Risk Factors, Aging and Incidence of Dementia; CI, confidence interval; RR, relative risk; SCI, severe cognitive impairment.

Bold identifies significant results.

RR and 95\% CI for development of SCI relative to the first quartile.

\begin{tabular}{lll}
\hline Measure & \multicolumn{2}{l}{ High risk of future development of SCI } \\
\cline { 2 - 3 } & $\begin{array}{ll}\text { CAIDE dementia risk } \\
\text { score } \geq 9\end{array}$ & $\begin{array}{l}\text { CAIDE dementia risk } \\
\text { score } \geq 10\end{array}$ \\
\hline Sensitivity & 0.76 & 0.50 \\
Specificity & 0.68 & 0.83 \\
Positive PV & 0.12 & 0.14 \\
Negative PV & 0.98 & 0.97 \\
Accuracy & 0.69 & 0.82 \\
\hline
\end{tabular}

CAIDE, Cardiovascular Risk Factors, Aging and Incidence of Dementia; HAAS, Honolulu-Asia Aging Study; PV, predictive value; SCI, severe cognitive impairment.

High risk is defined as a CAIDE dementia risk score of $\geq 9$ versus a score of $\geq 10$.

quartile have a $900 \%$ higher risk of later development of SCI than those with scores in the lowest quartile (RR = 10.131, CI: 4.66-22.04).

Table 4 displays measures of predictive capacity of the CAIDE dementia risk score as a screening tool for future development of SCI. Two sets of values are given based on different cut-off values for defining "high risk," one using a score of $\geq 9$ as high risk and the other setting the cut-off at $\geq 10$. As expected, using a higher cut-off value captures fewer true positives, thus reducing the sensitivity of the test $(0.76$ vs. 0.50$)$. Conversely, the lower cut-off value captures fewer true negatives, resulting in a decrease in specificity ( 0.68 vs. 0.83 ). The positive predictive value is low with either cut-off ( 0.12 and 0.14 , respectively), suggesting more individuals at high risk would be categorized as low risk. The negative predictive value is high for either cut-off $(0.98$ vs. 0.97), meaning most low-risk individuals would properly be categorized as low risk. The accuracy of the lower cut-off is less than that of the high cut-off ( 0.69 and 0.82 , respectively).

\section{Discussion}

While we found a significant association between the midlife CAIDE dementia risk score and later life SCI, the predictive ability of the score was low in our population of JapaneseAmerican men (c-statistics $=0.645 ; 95 \%$ CI: 0.62-0.67) Further, poor sensitivity $(0.50$ or 
0.76) means many of those truly at risk would not be identified as such. Using the higher cut-off $(\geq 10)$, the test would be correct more than $80 \%$ of the time. However, the majority of those correctly categorized would be true negatives.

We observed expected relationships between the development of SCI and components of the CAIDE dementia risk score. Specifically, those who developed SCI were older, had less education, had higher BMIs, and were more likely to have at least one APOE $\varepsilon 4$ allele. Although elevated blood pressure has been associated with cognitive impairment in this cohort $[9$, 10], we did not see this in our study using the CAIDE dementia risk score definition. Additionally, cholesterol levels have been shown to be associated with risk of Alzheimer's disease [11], but we saw no difference. It is possible that the use of anti-hypertensive or cholesterollowering medications may be masking any existing relationship [12]. Of interest to note is the protective effect of physical inactivity observed in this cohort. Leisure activity is believed to be one component that decreases the risk of dementia [13], which makes this finding counterintuitive. A previous study in the HAAS cohort found that physical activity benefitted primarily men with limited physical function rather than those with moderate or high physical function [14]. It is possible that our cohort has mostly moderate to high physical function, negating the effect of physical activity. However, this does not explain the observed protective effect.

Although some researchers have been able to replicate a moderate predictive capacity of the CAIDE dementia risk score [15-17], others have found results similar to those in this study. Kerut et al. [18] obtained the same c-statistics of 0.64 in a sample of African-Americans. Licher et al. [19] and Anstey et al. [20] found predictive capacities not much better than chance when validating the CAIDE dementia risk score across several cohorts (c-statistics range $=0.49-0.57$ ). However, it is important to note that the cohorts used in these two studies were comprised of older adults and the follow-up time was short. The CAIDE dementia risk score was developed using middle-aged respondents and a 20-year follow-up. It has been noted that some risk factors for dementia during midlife, such as high cholesterol or high BMI, may no longer confer increased risk in late-life [21-23]. Thus, the CAIDE dementia risk score may not perform as well among older adults.

Although the CAIDE dementia risk score has been validated in other populations [24-29], the poor predictive capacity observed in this study may be a result of specific characteristics of our cohort (e.g., Japanese ancestry or male gender), suggesting limited generalizability. In a review of studies coding dementia, Wilkinson et al. [30] found a large heterogeneity in accuracy estimates and suggested that setting-specific validation may be the best option. Alternatively, the CAIDE dementia risk score may be lacking important components for the prediction of future dementia. The original authors concede they did not have data for some factors they believe would have improved the score, including the presence of diabetes, waisthip ratio, and a family history of dementia [4]. The CAIDE dementia risk score is important in that it highlights modifiable risk factors prior to disease development. Identification and manipulation of these factors in midlife could reduce the development of dementia among the elderly.

\section{Conclusion}

Although the predictive ability of the CAIDE dementia risk score was low in this cohort, there was a significant association between the midlife risk score and development of SCI 25 years later. 
Chosy et al.: CAIDE Dementia Risk Score and HAAS

\section{Statement of Ethics}

Both the Honolulu Heart Program (HHP) and the Honolulu-Asia Aging Study (HAAS) studies were reviewed and approved by the Institutional Review Board of Kuakini Medical Center, Honolulu, Hawaii, USA.

\section{Disclosure Statement}

The authors have no conflicts of interest to declare.

\section{Funding Sources}

This work was supported by the National Institute on Aging (NIA) grants UF1AG053983 and UF1AG057707; Intramural Research Program, NIA; and the Office of the Assistant Secretary of Defense for Health Affairs under award No. W81XWH-15-1-0431. The content in this article does not necessarily reflect the official views of the United States Government.

\section{Author Contributions}

All authors contributed substantially to the completion of this analysis and manuscript.

\section{References}

1 Hou XH, Feng L, Zhang C, Cao XP, Tan L, Yu JT. Models for predicting risk of dementia: a systematic review. J Neurol Neurosurg Psychiatry. 2019 Apr;90(4):373-9.

2 Stephan BC, Tang E, Muniz-Terrera G. Composite risk scores for predicting dementia. Curr Opin Psychiatry. 2016 Mar;29(2):174-80.

3 Tang EY, Harrison SL, Errington L, Gordon MF, Visser PJ, Novak G, et al. Current developments in dementia risk prediction modelling: an updated systematic review. PLoS One. 2015 Sep;10(9):e0136181.

4 Kivipelto M, Ngandu T, Laatikainen T, Winblad B, Soininen H, Tuomilehto J. Risk score for the prediction of dementia risk in 20 years among middle aged people: a longitudinal, population-based study. Lancet Neurol. 2006 Sep;5(9):735-41.

5 White L, Petrovitch H, Ross GW, Masaki KH, Abbott RD, Teng EL, et al. Prevalence of dementia in older JapaneseAmerican men in Hawaii: The Honolulu-Asia Aging Study. JAMA. 1996 Sep;276(12):955-60.

6 Teng EL, Hasegawa K, Homma A, Imai Y, Larson E, Graves A, et al. The Cognitive Abilities Screening Instrument (CASI): a practical test for cross-cultural epidemiological studies of dementia. Int Psychogeriatr. 1994;6(1): 45-58.

7 White LR, Edland SD, Hemmy LS, Montine KS, Zarow C, Sonnen JA, et al. Neuropathologic comorbidity and cognitive impairment in the Nun and Honolulu-Asia Aging Studies. Neurology. 2016 Mar;86(11):1000-8.

8 Donahue RP, Abbott RD, Reed DM, Yano K. Physical activity and coronary heart disease in middle-aged and elderly men: the Honolulu Heart Program. Am J Public Health. 1988 Jun;78(6):683-5.

9 Peila R, White LR, Petrovich H, Masaki K, Ross GW, Havlik RJ, et al. Joint effect of the APOE gene and midlife systolic blood pressure on late-life cognitive impairment: the Honolulu-Asia aging study. Stroke. 2001 Dec; 32(12):2882-9.

10 Launer LJ, Ross GW, Petrovitch H, Masaki K, Foley D, White LR, et al. Midlife blood pressure and dementia: the Honolulu-Asia aging study. Neurobiol Aging. 2000 Jan-Feb;21(1):49-55.

11 Solomon A, Kivipelto M, Wolozin B, Zhou J, Whitmer RA. Midlife serum cholesterol and increased risk of Alzheimer's and vascular dementia three decades later. Dement Geriatr Cogn Disord. 2009;28(1):75-80.

12 Gelber RP, Ross GW, Petrovitch H, Masaki KH, Launer LJ, White LR. Antihypertensive medication use and risk of cognitive impairment: the Honolulu-Asia Aging Study. Neurology. 2013 Sep;81(10):888-95.

13 Karp A, Paillard-Borg S, Wang HX, Silverstein M, Winblad B, Fratiglioni L. Mental, physical and social components in leisure activities equally contribute to decrease dementia risk. Dement Geriatr Cogn Disord. 2006; 21(2):65-73.

14 Taaffe DR, Irie F, Masaki KH, Abbott RD, Petrovitch H, Ross GW, et al. Physical activity, physical function, and incident dementia in elderly men: the Honolulu-Asia Aging Study. J Gerontol A Biol Sci Med Sci. 2008 May; 63(5):529-35. 
Chosy et al.: CAIDE Dementia Risk Score and HAAS

15 Rawtaer I, Feng L, Yuen VH, Li J, Chong MS, Lim WS, et al. A Risk Score for the Prediction of Neurocognitive Disorders among Community-Dwelling Chinese Older Adults. Dement Geriatr Cogn Disord. 2016;41(5-6): 348-58.

16 Exalto LG, Quesenberry CP, Barnes D, Kivipelto M, Biessels GJ, Whitmer RA. Midlife risk score for the prediction of dementia four decades later. Alzheimers Dement. 2014 Sep;10(5):562-70.

17 Solomon A, Ngandu T, Soininen H, Hallikainen MM, Kivipelto M, Laatikainen T. Validity of dementia and Alzheimer's disease diagnoses in Finnish national registers. Alzheimers Dement. 2014 May;10(3):303-9.

18 Kerut SE, Lirette S, Saleh A, Turner ST, Benjamin EJ, Fornage M, et al. CAIDE risk score predictions of shortterm cognitive impairment in African Americans. Poster presented at: American Geriatrics Society 2018 Annual Meeting; May 3-5, 2018; Orlando, FL.

19 Licher S, Yilmaz P, Leening MJ, Wolters FJ, Vernooij MW, Stephan BC, et al. External validation of four dementia prediction models for use in the general community-dwelling population: a comparative analysis from the Rotterdam Study. Eur J Epidemiol. 2018 Jul;33(7):645-55.

20 Anstey KJ, Cherbuin N, Herath PM, Qiu C, Kuller LH, Lopez OL, et al. A self-report risk index to predict occurrence of dementia in three independent cohorts of older adults: the ANU-ADRI. PLoS One. 2014 Jan; 9(1):e86141.

21 Stewart R, White LR, Xue QL, Launer LJ. Twenty-six-year change in total cholesterol levels and incident dementia: the Honolulu-Asia Aging Study. Arch Neurol. 2007 Jan;64(1):103-7.

22 White L, Launer L. Relevance of cardiovascular risk factors and ischemic cerebrovascular disease to the pathogenesis of Alzheimer disease: a review of accrued findings from the Honolulu-Asia Aging Study. Alzheimer Dis Assoc Disord. 2006 Jul-Sep;20(3 Suppl 2):S79-83.

23 Stewart R, Masaki K, Xue QL, Peila R, Petrovitch H, White LR, et al. A 32-year prospective study of change in body weight and incident dementia: the Honolulu-Asia Aging Study. Arch Neurol. 2005 Jan;62(1):55-60.

24 Ecay-Torres M, Estanga A, Tainta M, Izagirre A, Garcia-Sebastian M, Villanua J, et al. Increased CAIDE dementia risk, cognition, CSF biomarkers, and vascular burden in healthy adults. Neurology. 2018 Jul;91(3):e217-26.

25 Hooshmand B, Polvikoski T, Kivipelto M, Tanskanen M, Myllykangas L, Mäkelä M, et al. CAIDE Dementia Risk Score, Alzheimer and cerebrovascular pathology: a population-based autopsy study. J Intern Med. 2018 Jun; 283(6):597-603.

26 Harrison SL, de Craen AJ, Kerse N, Teh R, Granic A, Davies K, et al. Predicting risk of cognitive decline in very old adults using three models: the Framingham Stroke Risk Profile; the Cardiovascular Risk Factors, Aging, and Dementia model; and oxi-inflammatory biomarkers. J Am Geriatr Soc. 2017 Feb;65(2):381-9.

27 Enache D, Solomon A, Cavallin L, Kåreholt I, Kramberger MG, Aarsland D, et al. CAIDE Dementia Risk Score and biomarkers of neurodegeneration in memory clinic patients without dementia. Neurobiol Aging. 2016 Jun;42: 124-31.

28 Kaffashian S, Dugravot A, Elbaz A, Shipley MJ, Sabia S, Kivimäki M, et al. Predicting cognitive decline: a dementia risk score vs. the Framingham vascular risk scores. Neurology. 2013 Apr;80(14):1300-6.

29 Reijmer YD, van den Berg E, van Sonsbeek S, Dekker JM, Nijpels G, Stehouwer CD, et al. Dementia risk score predicts cognitive impairment after a period of 15 years in a nondemented population. Dement Geriatr Cogn Disord. 2011;31(2):152-7.

30 Wilkinson T, Ly A, Schnier C, Rannikmäe K, Bush K, Brayne C, et al.; UK Biobank Neurodegenerative Outcomes Group and Dementias Platform UK. Identifying dementia cases with routinely collected health data: A systematic review. Alzheimers Dement. 2018 Aug;14(8):1038-51. 